\title{
Censos e construção nacional no Brasil Imperial*
}

Tarcisio R. Botelho são revisada da PartellI

O leitor que puder observar o significado do termo $\mathrm{N}$ ação nos principais dicionários da língua portuguesa desde o século XVIII perceberá claramente como ele sofre transformações profundas. Uma incursão por três dos mais importantes dicionários portugueses que surgiram ao longo dos sécude minha tese de doutorado em H istória Social pela USP, orientada pela professora Eni Ios XVIII eXIX deixa isso claro. D e um significado mais próximo à definide M esquita Samara. ção de reino e senhorio, presente em Bluteau (1712), passamos para considerações sobre cultura e governo comuns, conforme a segunda edição de M oraes Silva (1813). Entretanto, na oitava edição de M oraes Silva (1891), em fins do século XIX, o conceito tornara-se articulado ao de Estado e próximo ao de cidadania. Já em Caldas Aulete (1881) podemos perceber uma maior clareza do conceito, também abertamente articulado a Estado e cidadania, mas já prevendo os inúmeros caminhos que a nação poderia percorrer nas suas relações ambíguas com os Estados e com a cultura.

Portanto, ao findar-se o século XIX, o termo N ação aproximava-se do conceito de Estado, articulava-se claramente com o de cidadania, relacionava-se com os de povo e cultura. Pode-se dizer que os dicionários portugueses expressam os contornos que a questão nacional assumira na segunda metade do século XIX e que transparece na bibliografia corrente sobre o tema'.

1. Exercício semelhante que compara o significado do termo $\mathrm{Na}$ ção em diversos dicionários europeus pode ser encontrado em H obsbawm (1990, pp. 27-61). 
2. D evo lembrar que os dicionários citados, embora tenham sido editadosem Portugal, eram de ampla circulação no Brasil, ondepraticamente não se editavam dicionários. D e uma lista dos trinta mais importantesdicionáriosdalíngua portuguesa editados nos séculos XVIII e $X I X$, apenas três foram editados no Brasil, sendo um deles a reedição do original português (cf. Faria, 1859). O soutros são Pinto (1832) e Soares (1875). Agradeço a $\mathrm{M}$ arcelo de $\mathrm{M}$ agaIhães G odoy, do C edeplar/Face da UFM G, por me ceder o levantamento dos dicionários da língua portuguesa.
M ais importante ainda: parece-me claro que no Brasil o século XIX foi marcado por essa transformação profunda do significado de nação, bem como de sua ampla articulação com o Estado. Se aceitarmos essas considerações, o estudo do processo de construção da nação no Brasil deve necessariamente fazer-se a partir do estudo do seu período imperial². O sobjetivos deste trabalho, contudo, são mais modestos. Pretendo apenas perceber como o tema "nação" se articulou, no século XIX, com as tentativas de realizar os primeiros levantamentos censitários brasileiros, especialmente em 1852 e 1872, influenciando-os e sendo por eles influenciado.

\section{Que é uma nação?}

$\mathrm{N} \mathrm{a}$ conhecida formulação de Benedict Anderson, segundo a qual a nação pode ser vista como "uma comunidade política imaginada - e imaginada como implicitamente limitada e soberana" (1989, p. 14), associa-se 0 surgimento das comunidades imaginadas das nações ao declínio de outras comunidades, como as religiosas ou dinásticas. As antigas colônias européias das Américas apareceram como áreas de desenvolvimento precoce desse novo tipo de solidariedade, antecipando até mesmo sua disseminação na Europa como um todo.

Segundo Eric H obsbawm, de início, e nos marcos da Revolução Francesa, formulou-se a equação nação $=$ Estado = povo e, especialmente, povo soberano (cf. H obsbawm, 1990, p. 32). Entretanto, com o avançar do sé culo XIX, observaram-se modificações, pelos ideólogos liberais burgueses, nas concepções acerca de Estado-nação, assumindo importância fundamental temas como etnicidade, língua comum, religião, território e lembranças históricas comuns (cf. Idem, p. 33).

Para Charles Tilly (1996), os Estados nacionais caracterizar-se-iam pela união, numa estrutura central relativamente coordenada, de importantes organizações militares, extrativas, administrativas e às vezes até distributivas e produtivas. É de especial relevância o reconhecimento de que o Estado nacional não se originou de um modelo preconcebido, mas foi o resultado das necessidades, dos embates com outros Estados e das lutas e negociações com classes diferentes da população (cf. I dem, pp. 75-76).

0 estreito relacionamento que se desenvolve entre os processos de construção do Estado e de construção da nação é também explicitado por Reinhard Bendix (1996), embora em direção um pouco diversa. Esse autor analisa o processo de legitimação da autoridade pública por meio da buro- 
cratização que caracteriza o que ele chama de Estado-nação ocidental. Portanto, o processo de construção desse tipo de comunidade política passa pela possibilidade de afirmação de uma autoridade pública legítima, com base na burocracia, abrangendo todo o território a ela subordinado. Ao mesmo tempo, exige-se o reconhecimento de direitos básicos para os membros dessa comunidade política.

Todas essas abordagens acerca da construção do Estado e da nação estão, de uma forma ou de outra, relacionadas com esses processos no Brasil do século XIX, ainda que de uma forma negativa ou conflituosa. Para compreender a construção dos censos em suas várias articulações com o Estado imperial brasileiro e os anseios das elites em torno da construção da nação, temas como o pertencimento à comunidade nacional, os vários critérios de definição da nacionalidade ou os padrões de relacionamento entre o Estado e a sociedade devem ser continuamente resgatados e articulados.

O s estudos sobre a construção da nação no Brasil tendem a associar-se a momentos históricos diferentes. D e um lado, tem-se os trabalhos vinculados ao tema do nativismo, aproximando-o de um protonacionalismo. D aí se estabelece um continuum quevai até meados do século XIX, quando o tema da nacionalidade aparece sobretudo associado à literatura e à produção intelectual de modo mais amplo (cf. Burns, 1968). 0 tema da construção nacional nesse período apresenta problemas conceituais e contornos polêmicos, nos quais não me deterei aqui ${ }^{3}$. Q uero apenas ressaltar que no século XIX essa permanece uma área de poucos estudos. Alguns trabal hos abordam a questão ao tratar do período em torno da Independência, quando vários conceitos de nação estiveram em debate (cf. D ias, 1986; Gauer, 2001; Lyra, 1994; Paz, 1996; Ribeiro, 1995; Santos, 1985, 1986). Após esse momento, o processo de construção da nação brasileira só volta a preocupar os historiadores e cientistas sociais a partir da década de $1870^{4}$. Tal período é visto como uma ruptura tanto do ponto de vista da produção intelectual como das próprias possibilidades de difusão de sentimentos de nacionalidade a camadas mais amplas da população. $M$ as é realmente $a \mathrm{Re}$ pública, e especial mente à medida que se avança no século $X X$, o período da história brasileira identificado com o processo de construção e difusão de uma identidade nacional ${ }^{5}$.

$\mathrm{Na}$ abordagem que pretendo adotar, espero superar alguns desses limites para ver nos censos demográficos um elemento integrante do processo de reconhecimento da nacionalidade brasileira e, portanto, formador da nação. Ao se tratar do período imperial brasileiro, tende-se a vêlo como
3. Uma boainvestigação sobre o nativismo pode ser encontrada em Silva(1997), especialmente no capítulo 3. O bra importantesobreo processo de construção da nação entre os fins do século XVIII eaprimeira metade do século $X I X$, equeusarei como guia para este tópico, é Barman (1988).

4. U ma exceção interes santeéPaz (1996), que procura analisar esse processo ao longo de todo o século XIX.

5. Sobre a importância da "geração de 1870", ver Q ueiroz (1989), Schwarcz (1993) e Alonso (2002). Sobrea importância dos intelectuais na construção daidentidadenacional brasileira duranteaRepública, ver Oliveira (1990), M otta (1992), Garcia Jr. (1993), G omes (1996) eC arvalho (1998). U ma argumentação persuasiva acerca dacentralidadedosprojetos de construção nacional no período republicano podeser encontrada em Reis (1985). 
6. H á, no pensamento político esocial brasileiro e em parte da nossa historiografia, umacondenação da precedência do Estado sobre a na ção no Brasil, bastante difundida a partir de considerações como ade quenossa sociedade foi construída pelo Estado ou dequenão tínhamos um povo. Entretanto, essa éa marca constitutiva dos Estados nacionaismodernos, conformesedepreendedadiscussão travada no item anterior. U ma crítica dessa abordagem no pensamento brasileiro, embora com um ponto devistadiferentedo que venho adotando aqui, podeser encontradaem M agnoli (1997, em es pecial pp. 116-131). um momento em que a necessidade de consolidar um centro de poder em um território tão vasto quanto a colônia portuguesa na América tornou 0 imperativo da construção do Estado muito mais relevante do que o da nacionalidade (cf. Reis, 1985, p. 191). Como, porém, a construção da nação é um processo contínuo e articulado com a construção do Estado, não deixa de ser relevante identificar os momentos em que essa interação se evidencia. Assim, se a nação é construída a partir de uma ação positiva do Estado, ela interage com o processo de construção do Estado, reforçando-o e consolidando-o. N o Brasil, se a consolidação do Estado imperial precedeu a formação da nacionalidade, o avanço desta reforçou os laços de solidariedade requeridos pela constituição de uma comunidade política, nos termos identificados por Reinhard Bendix ${ }^{6}$.

0 processo de independência brasileiro foi marcado sobretudo pelo estabelecimento, a partir de 1808, da Corte portuguesa no Rio de Janeiro, antiga sede do poder colonial. A transferência do centro da metrópole para uma área colonial provocou um processo de convergência em torno da cidade que abrigava a C orte e o enraizamento de interesses na região centro-sul da C olônia, naquilo que M aria 0 dila da Silva D ias (1986) chamou de "interiorização da metrópole".

Entre as tarefas assumidas pela elite política estabelecida, sobressaiu-se a busca da supremacia sobre as outras áreas da colônia portuguesa na Amé rica. A luta desenrolou-se em torno do progressivo estabelecimento da supremacia da nação sobre as diversas pátrias regionais, a fim de superar os riscos da anarquia social e racial (cf. Barman, 1988, caps. 6 e 7), conflitos que só começaram a ser resolvidos após o golpe da maioridade, que deu início ao reinado efetivo de dom Pedro II e restaurou o exercício do poder moderador. 0 s anos que se seguiram até os princípios da década de 1850 marcaram o triunfo, no Brasil, do conceito de Estado-nação. A partir daí, seus líderes políticos passaram a concentrar as atenções na complementação das estruturas estatais e na busca da consolidação da nacional idade (cf. I dem, p. 217), tarefas essas facilitadas pelo surgimento de uma nova geração da elite política que considerava a nacionalidade brasileira axiomática, pois já nascera sob o predomínio do Estado independente (cf. Idem, p. 228).

$\mathrm{N}$ a medida em que avançou o Segundo Reinado, outros elementos foram se incorporando ao processo de construção da nação. José M urilo de C arvalho chama a atenção para a importância da G uerra do Paraguai (18651870) como um grande fator na formação de uma identidade brasileira (cf. Carvalho, 1995, p. 58; Burns, 1968, pp. 47-48), como também o 
esforço em se formar um pensamento acerca da identidade brasileira, tare fa em que se empenhou a geração que apareceu na cena intelectual a partir de 1870 (cf. Q ueiroz, 1989; Schwarcz, 1993)7.

O Instituto H istórico e Geográfico Brasileiro também foi importante nesse processo. Do ponto de vista historiográfico, ele se encarregou da tarefa de pensar a nação, o que, segundo M anoel Luís Sal gado G uimarães (1988), se fez de acordo com postulados típicos de uma história comprometida com 0 desvendamento do processo de gênese da nação ${ }^{8}$. $M$ as 0 instituto não foi apenas o local de formulação de um saber historiográfico. A geografia tinha seu espaço garantido no seio da instituição, sem que houvesse uma distinção precisa entre textos dos dois tipos nas publicações do instituto (cf. M agnoli, 1997). A geografia cumpria o mesmo papel da história, por meio da definição e delimitação do território como condições essenciais para a construção da nação: "assim como a tradição é a pátria no tempo, o território é a pátria no espaço" (M agnoli, 1997, pp. 109-110)9.

0 instituto abrigou também debates acerca da população brasileira. $M$ ais identificados com a geografia, os trabal hos estatísticos, embora mais raros, foram alvo das preocupações de seus membros. M as o que considero mais relevante, vendo o instituto como o espelho da elite política eintelectual do Império, éperceber a importância que o estudo da população - que passou a ser tratada cada vez mais como uma variável central para a descrição e a identificação da nacionalidade - pode ter assumido para essa elite.

Todo esse o processo de construção da nação foi também um processo de reconhecimento de seus componentes, ainda que de maneira hierarquizada. Creio poder perceber na elite política e intelectual brasileira, no que diz respeito às preocupações com os levantamentos censitários, um comportamento marcado por um movimento que vai da contagem dos habitantes do Brasil, ainda pautada pelas preocupações herdadas da situação colonial, para o esforço em medir a nação, o que por sua vez estaria articulado não mais com interesses metropolitanos, mas com temas como a implantação de políticas públicas (fim da escravidão, por exemplo), a questão eleitoral e 0 próprio reconhecimento do rosto que assumiria o povo brasileiro ${ }^{10}$.

Contar os habitantes do Brasil: dos levantamentos parciais ao censo nacional

Conforme assinalei, o processo de construção da nação no Brasil (assim como em outros países) articulou-se com o processo de construção do Estado. 0 que nos diferenciou, especialmente em relação às demais colô-
7. Esse foi o momento em quenasceu ecomeçou a se difundir o que Wanderley Guilherme dos Santos chama de "naturalismo histórico": "os processos sociais são agora vistos como processos naturais, históricos, ondeasdiversaspartes da sociedade se integram funcionalmente. $D$ aí deriva-sefacilmente a idéia de que o processo brasileiro é patológico, poisa evolução 'normal' da sociedade tem sido desviada ou impedida pela imposição de fórmulas políticas não geradas naturalmente" (1978, pp. 52-53).

8. Sobre o IH GB, ver Schwarcz (1993) e D omingues (1986).

9. U m exemplo dessa valorização do conteúdo historiográfico dare vista do instituto pode ser visto em Schwarcz (1993, cap. 4).

10. Para uma discussão semelhante, porém com perspectiva diferente, ver Paz (1996, pp. 255303). 


\section{Para maior detalha} mento das condições de elaboração desses levantamentospopulacionais, ver Botelho (1998), em especial a parte I.

12. M inas Gerais, 1823: Arquivo Nacional, Códice 808 (doravante: AN C808), v. 1, f. 1935s. M inas $G$ erais, 1833-1835: $M$ artins (s/d). Santa Catarina, 1828: AN C808, v. 3, f. 93. Rio Grandedo N orte, 1835: BibliotecaN acional, se ção de M anuscritos, I32,10,5. Sergipe, 1834: Arquivo $\mathrm{Nacional,} \mathrm{Mi}$ nistério do Reino e do Império (doravante AN M RI), cX. 761. M ato Grosso, 1826: BibliotecaN acional, seção deM a nuscritos, I-31,19,16. nias européias nas Américas, foi o grau em que o Estado surgido da independência mostrou-se herdeiro do Estado português. Essa continuidade pode ser vista nos levantamentos populacionais realizados até pelo menos o período regencial, nos quais se percebem os mesmos procedimentos e as mesmas preocupações pragmáticas que orientavam a Coroa portuguesa. $0 \mathrm{~s}$ funcionários encarregados dos censos eram praticamente os mesmos utilizados nos momentos anteriores à Independência, e os capitães de ordenanças e inspetores de quartei rões elaboravam listas locais contendo a discriminação de todos os habitantes residentes em seus distritos. Essas listas nominativas eram enviadas aos governos centrais das províncias, os quais se encarregavam de apurar os resultados e, quando solicitados, enviá-los à Corte do Rio de Janeiro. Eventualmente, as listas davam lugar a tabelas que já traziam resultados condensados sobre a população. Com o passar do tempo, os capitães de ordenanças foram progressivamente substituídos pelos juízes de paz e, a partir de 1841, pelos delegados e subdelegados de polícia ${ }^{11}$.

As categorias censitárias também revelavam permanências significativas em face da experiência colonial. Se a divisão entre livres e escravos (e, eventualmente, libertos) era uma decorrência óbvia da segmentação fundamental que marcava a sociedade brasileira, a preocupação em registrar a cor era certamente uma herança portuguesa muito importante. A maior parte dos levantamentos censitários da época dividia a população em pelo menos três segmentos: os brancos; a população de ascendência africana nascida no Brasil, mestiça ou não; e os pretos. O nde a população indígena assumia proporções significativas, essa categoria também se incorporava aos censos, descrita como caboclos. Em geral, os descendentes de africanos nascidos no Brasil eram classificados como crioulos ou, no caso daqueles nascidos de relações inter-raciais, como mulatos, pardos e/ ou mestiços. Em contraposição, os africanos tendiam a aparecer como negros ou pretos. Eventualmente, a diferença entre africanos e crioulos desaparecia sob a denominação de negros ou pretos. $O$ censo organizado para a província de M inas $G$ erais em 1823, por exemplo, dividiu a população em brancos, índios, pardos, crioulos e pretos, e o realizado entre 1833 e 1835, por sua vez, preocupou-se em identificar os brancos, os pardos e os pretos. Santa Catarina, em 1828, apresentou sua população segmentada em brancos, índios, pardos e pretos. O Rio Grande do N orte, em 1835, agregou sua população em brancos, pardos, pretos e índios, da mesma forma que o Sergipe no ano anterior e 0 $M$ ato G rosso em 1826 ${ }^{12}$. Essa herança portuguesa, ou mesmo ibérica, teria 
depois uma importância significativa na construção da nação brasileira, e com isso me refiro à centralidade dada à questão racial na definição da nossa nacionalidade ${ }^{13}$.

Ademais, era relativamente comum serem encontradas faixas etárias que sobretudo separavam crianças, jovens, adultos e vel hos. 0 s censos citados anteriormente exemplificam esse aspecto. M inas G erais em 1823 trazia faixas etárias qüinqüenais até os vinte anos e decenais a partir daí; mas em 1833-1835 as faixas eram de quinze anos. Sergipe, em 1834, agregou seus habitantes em faixas decenais, da mesma forma que o Rio G rande do N orte o fizera em 1822, 1827 e 1835. Transparecia, nesse caso, a ambigüidade entre 0 interesse de contar os habitantes para avaliar seu potencial (por exemplo, em oferecer candidatos ao recrutamento militar) e a busca de informações relevantes do ponto de vista demográfico.

Essa continuidade entre os levantamentos populacionais das primeiras décadas do I mpério e seus antecessores coloniais posicionava-os no mesmo patamar. Eram investigações que ainda tinham por finalidade medir as "forças" do Estado e atendiam a uma lógica de valorização dos seus aspectos extorquidores. Ainda em 1818, o conselheiro Antônio Rodrigues Velloso de O liveira, encarregado pela M esa do D esembargo do Paço de sugerir uma nova divisão dos bispados brasileiros, baseou sua argumentação sobretudo na extensão territorial e na população presente. Para ele tratava-se de um "negócio tão sério, e grave, e ao mesmo tempo tão útil, e necessário ao bem comum dos povos, e indubitável aumento das forças reais do Estado" (O liveira, 1866, p. 159; grifos meus). O s requerimentos enviados pelo parlamento do Primeiro Reinado aos ministros também guardavam sempre esse tom: seria muito difícil, ou até mesmo impossível, tomar decisões acerca dos destinos da administração pública sem conhecer o contingente da população brasileira (cf. Botelho, 1988, parte I). U ma "M emória Estatística do Império do Brasil", de 1829 mas publicada na Revista do Instituto H istórico e Geográfico Brasileiro em 1895, comungava desse espírito ao afirmar que "uma povoação ativa e industriosa é o principal agente da riqueza, força e poder de um Estado. 0 aumento progressivo da povoação é o termômetro da prosperidade da N ação" (t. LVIII, parte I, $1^{\circ}$ e e 20 trimestres; grifos meus). Afinada com tais preocupações, uma "M emória e considerações sobrea população do Brasil", de autoria de $H$ enriqueJ orge Rebello, impressa na Bahia em 1836 e reeditada na revista do instituto três décadas depois, tinha como objetivo identificar "os obstáculos que se opõem ao progresso da sua população" (1867, t. XXX, 1ํ trimestre, p. 7). A supera-
13. A título de comparação, é significativo que, nosEstadosU nidos, a divisão básica entrelivres, escravos e índios, estabelecida desdeo primeiro censo de1790, visasse a atender aos preceitos daConstituição de 1787 quanto à distribuição da representatividadeno Congresso edosencargosfiscaisdevidospelos Estados ao governo federal, ambos baseados no contingentepopulacional de cada unidade dafederação (cf. Anderson, 1988, pp. 7-13). 
14. U maanáliseinteressante acerca do sistema eleitoral durante $\mathrm{olm}$ pério podeser encontrada em Carvalho (1988, cap. 5).

15. D iscussões acercada definição de cidadania no Brasil Imperial podem ser encontradasem Carvalho (1988) eSantos(1978). Em Graham (1997, parte 2), há um estudo do funcionamento da qualificação devotantes, apontando seus problemas e vícios.

16. Rio Grandedo N orte, 1846: AN -M RI, cX. 761. Espírito Santo, 1848: AN-C 808, v. 1. Bahia, 1848: AN -M RI, cx. 761.

17. Anais do Parlamento Brasileiro, Senado (doravante, APB-S), sessão de 22/8/1850. ção desses obstáculos, portanto, seria importante para o Brasil, pois aqui a população existia desfalcada e precisava de reforma.

0 início do Segundo Reinado marcou o progressivo redirecionamento das preocupações com os levantamentos populacionais. A construção de uma ordem política mais sólida, permitindo a superação dos conflitos e incertezas característicos do período regencial, esteve na raiz da consolidação da monarquia brasileira. Como desafio a ser enfrentado pela nova ordem, sobressaía o problema de se estabelecer as bases de um sistema eleitoral confiável. N ão discutirei aqui as características e as transformações do sistema eleitoral brasileiro durante o período imperial ${ }^{14}$, mas quero chamar a atenção para o fato de que se tornou essencial conhecer melhor a população brasileira a fim de estabelecer um controle sobre tal sistema. Abriu-se, assim, mais uma fonte de demandas por informações demográficas mais precisas, que se cristalizou na legislação el eitoral de 1846, prevendo a realização de censos a cada oito anos (Lei no 387, de 19 de agosto de 1846, art. 107). 0 período intercensitário refletia bem as preocupações eleitorais, já que visava a cobrir o lapso de duas legislaturas.

Urgia, pois, solucionar de imediato os problemas oriundos da necessidade de fixar a dimensão dos colégios eleitorais. D isseminaram-se nessa época os levantamentos da população livre das províncias, que buscavam determinar o contingente de população do qual sairiam os "cidadãos ativos", ou seja, aqueles que poderiam potencialmente votar, desde que provassem, no processo de qualificação de votantes, que atendiam às exigências legai $s^{15}$. Na elaboração de muitos dos quadros da população livre, manteve-se a divisão das cores, embora essa não fosse uma categoria relevante para seus fins, como podemos ver, por exemplo, no Rio Grande do N orte em 1846 ou no Espírito Santo e na Bahia em $1848^{16}$. Reforçavamse, pois, procedimentos consagrados, mesmo em um momento que, a rigor, os tornava desnecessários.

A carência de dados seguros sobre a população brasileira e as novas esferas da vida pública que estavam demandando tais informações levaram a se pensar na execução de um censo nacional. Essa medida ressurgiu no parlamento em 1850, quando o Senado incorporou, em emenda ao projeto de orçamento para 0 ano de 1851 a 1852, a autorização para o governo despender o que fosse necessário para levar a efeito o censo geral do Impé rio. A emenda nem chegou a ser justificada pelo seu autor, o senador $C$ ândido Batista de O liveira; segundo ele, sua simples enunciação já justificava a conveniência do artigo proposto ${ }^{17}$. Na Câmara dos D eputados, houve 
apenas uma observação do deputado padreVenâncio H enriques de Rezende, questionando a necessidade de uma comissão central, quando entendia ser melhor deixar 0 trabalho a cargo das províncias ${ }^{18}$. A ausência de debates sobre o tema derivou provavelmente da enorme concentração de projetos polêmicos naquela legislatura e mais especificamente naquele ano, em que foram aprovados o fim do tráfico de escravos, o Código Comercial e a Lei de Terras. A emenda sobre o censo, aliás, apareceu como uma idéia anexa à defesa que $\mathrm{o}$ senador $\mathrm{H}$ olanda $\mathrm{C}$ aval canti fazia da necessidade de criar 0 registro de terras, pois via os dois eventos (registro de terras e censo demográfico) como interligados a uma lógica de instrumentalização do Estado ${ }^{19}$. Ao que parece, o senador Batista de O liveira aproveitou-se da idéia e apresentou-a como sua.

A legislação decorrente da emenda orçamentária sobre o censo teve sua aplicação impedida pela explosão de uma revolta popular no N ordeste, já que os insurgentes viam no registro civil e no censo duas ameaças frontais. A substituição do registro paroquial de batismos, casamentos e óbitos apontava para uma laicização indesejada e estranha aos habitantes do interior do país. 0 censo, por sua vez, foi encarado como 0 caminho para o recrutamento militar, o aumento dos impostos e até mesmo a reescravização da população livre de cor. Ironicamente, o regulamento sobre o censo não continha o quesito $\operatorname{cor}^{20}$. A população demonstrava, pois, estar bastante informada acerca dos acontecimentos que atingiam o país, apesar de dar a eles uma interpretação peculiar. As guerras do sul em que o Brasil estava envolvido no momento eo fim do tráfico aprovado recentementepelo parlamento acenderam de imediato o temor pela utilização dos trabal hos estatísticos com o fito de solucionar esses dois problemas da elite brasileira: 0 aumento da força militar e a manutenção da mão-de-obra escrava.

Em certa medida, poderíamos concordar com a afirmação de Roderick Barman (1988, p. 236) de que os conflitos em torno do censo de 1852 seriam atribuídos à dicotomia preval ecente entrea nação real ea oficial ${ }^{21}$. A nação oficial afirmava-se por meio do processo de crescente consolidação do Estado e da ordem monárquica. 0 avanço da discussão sobre a cidadania, a resolução de demandas até então emperradas (a questão do tráfico e da terra, por exemplo) e outros serviam para dar à elite política um senso de pertencimento à nova comunidade imaginada. Entretanto, esse pertencimento não se espalhava por todas as parcelas da população (mesmo deixando de se considerar a população escrava). A cidadania restringida impossibilitava a construção de uma comunidade política mais ampliada, sustentácu-
18. Anais do Parlamento Brasileiro, Câmara dos $D$ eputados (doravanteAPB-CD ), sessão de 29/8/1850.

19. APB-S, sessão de14/ $8 / 1850$.

20. Segundo o visconde deM onteA legre, ministro do Império à época, essas revoltas foram estimuladas pelo boato de que o registro "só tinhapor fim escravizar a gente de cor". Em seu depoimento, o ministro registrou a ocorrência de distúrbios, alguns de muita gravidade, nas províncias da Paraíba, do Ceará, de Alagoas, Sergipe e Pernambuco (cf. Silva, [1870] 1986).

21. A dicotomia entreo oficial eo real perdesentido quando se constatam as estreitas relações queambosmantinham, por exemplo, nos momentos das eleições; especificamente sobre as eleições, ver Graham (1997). 
22. Sobrealei deterras, visõesdistintasaparecem em M artins (1979), Costa (1987), Carvalho (1988, pp. 84-106) e Smith (1990).
23. APB-CD, sessão de $15 / 7 / 1870$. lo do processo de construção do Estado nacional. A lei de terras mostravase bastante restritiva, dificultando 0 acesso legal a ela por parte da população pobre e iletrada22.

Por outro lado, as longas distâncias, agravadas pela precariedade das comunicações, e a modéstia do aparelho estatal, inviabilizando a construção de uma autoridade pública legítima, dificultavam o desempenho de tarefas que poderiam resultar em fortalecimento progressivo dessa mesma autoridade pública. D aí a desconfiança quando do surgimento de demandas que se contrapunham aos procedimentos tradicionais, bem exemplificada na resistência ao censo e ao registro civil. Pode-se dizer que o censo de 1852 fracassou porque ainda não havia condições mínimas de reconhecimento, por parte da população brasileira, de que ela real mente se integrava a essa comunidade ampliada. C reio ser possível afirmar que, quando se intentou, em 1852, medir a nação, aqueles que eram vistos como seus componentes não se sentiam como tal. Percebiam, no máximo, a presença ameaçadora do Estado; não conseguiam, ademais, ver-se refletidos nele.

Medir a nação: a construção do censo de 1872

0 fracasso do censo de 1852 arrefeceu os ânimos daqueles que 0 viam como uma necessidade do Estado imperial brasileiro. Apenas em 1870 voltou à baila a necessidade de enfrentar esse problema, tarefa novamente assumida por um gabinete conservador. Paulino J oséSoares de Souza, como ministro do Império, apresentou um projeto de lei à Assembléia Geral prevendo o censo do Império e o registro civil. Como justificativa, falava da falta de dados sobre a população tolhendo o legislador e embaraçando 0 administrador na solução de graves problemas, já que a nova proposta aparecia mais claramente articulada com as demandas do momento: a Lei do Ventre Livre, que vinha sendo discutida nesse mesmo ano, tornava imprescindível conhecer a população escrava do sexo feminino; ademais, o empenho do ministro em atacar o problema da educação primária dependia, segundo seu próprio depoimento, de se averiguar de forma mais acurada a população infantil a ser atendida. Por outro lado, os principais obstáculos à execução dos censos, acreditava o ministro, estavam naquele momento superados. Com o fim da G uerra do Paraguai, o receio de novos impostos e do recrutamento estava afastado: "A nova era da paz que há pouco encetamos exclui a idéia de contribuições extraordinárias e de aprestos militares"23. 
O parecer da Comissão de Estatística da Câmara dos D eputados, que examinou a proposta, apoiou-a, enfatizando outros aspectos que a tornavam urgente do ponto de vista das elites políticas imperiais. Assim, a ne cessidade da estatística oficial para o governo dos povos era universal mente proclamada, e as nações que procuravam caminhar na vanguarda da civilização consideravam-na um dos ramos importantes do serviço público. N os Congressos Internacionais de Estatística estavam sendo estabelecidas regras recomendadas a todos os povos civilizados: "a estatística oficial já não é apenas uma necessidade das nações, é moralmente um quase compromisso internacional, que um dia há de ser regulado por convenções entre os Estados no interesse da civilização"24. 0 projeto prepararia o país para tal compromisso, um encontro com a civilização.

$\mathrm{N}$ os debates que se seguiram, as objeções ao projeto referiram-se sobretudo a seus aspectos práticos e legais. Falava-se do caráter supérfluo da lei, pois já existiam outras sobre a mesma matéria ${ }^{25}$, e a concessão de um cré dito virtualmente ilimitado para execução do recenseamento também despertava receios ${ }^{26}$. Lembrou-se, ainda, da resistência despertada pela lei de 1850, chamando-se a atenção para a conveniência de não promover uma implantação tão radical do registro civil'27. Todavia, reconhecia-se a importância dessa tarefa, e o deputado José de Alencar, com um uso da história típico da época, lembrou que a estatística "tem florescido nos períodos que se tornam notáveis pelo desenvolvimento das luzes e prosperidades públicas", citando os períodos de Augusto, Luís XIV e N apoleão28.

A provado sem muitas modificações entre os deputados ${ }^{29}$, o projeto seguiu para o Senado. Também ali não houve uma contestação da rel evância. 0 parecer da Comissão de Estatística do Senado afirmava que "somente em vista de tais e tão importantes dados podem os poderes do Estado conhecer a força do país e assentar sobre uma larga base, e com segurança e proveito público, muitas das medidas legislativas ou administrativas, que são urgentemente reclamadas"30. 0 senador Pompeu, que em vários discursos contestou a viabilidade do censo como vinha sendo planejado, concordava com a necessidade da estatística, pois para ele "o conhecimento do número dehabitantes do país éa primeira condição para um governo regular, já não digo representativo" ${ }^{31}$. A discussão, ademais, limitou-se ao ataque (pelo senador Pompeu) e à defesa (pelo senador Figueira de $\mathrm{M}$ elo) do censo realizado na Corte e que tivera o propósito deliberado de servir de ensaio para o do Império como um todo ${ }^{32}$. Em primeiro de setembro de 1870, 0 projeto foi aprovado com a mesma redação dada pelos deputados.
24.APB-CD, sessão de $18 / 7 / 1870$.

25. APB-CD , sessões de20/7/1870 (deputado Andrade Figueira) e 3/8/1870 (deputado Andrade Figueira).

26. APB-CD , sessões de $3 / 8 / 1870$ (deputados Araújo Lima e AndradeFigueira) e 4/ 8/1870 (deputado José de Alencar).

27. APB-CD , sessão de 4/8/1870 (deputado JosédeAlencar). Foi sugerido que o governo aproveitasse os párocos, tornando-os responsáveis, mediante o pagamento de uma módica quantia, pelo registro civil. Assim, eles apenas adaptariam uma função quejádesempenhavam e o governo não levantariasuspeitaseresistências na população.

28.APB-CD , sessão de 4/8/1870.

29. Apenas houve a dilatação do prazo desua realização, reconhecendo-se que seria impossível executá-lo até a data inicialmente prevista (31 de dezembro de 1870), euma peque na mudança na estrutura da diretoria que 0 executaria; APB-CD, sessão de 12/8/1870. 
30.APB-S, sessão de 23/8/1870.

31. APB-S, sessão de 23/8/1870 (senador Pompeu).

32. APB-S, sessões de 23/8/1870, 27/8/1870, 29/8/1870 e30/8/1870.

33. Ver: "Parecer sobre 0 aldeamento dosíndios U iacurus, eGuanás, com adescrição dosseususos, religião, estabilidade, e costumes, por Ricardo de Almeida Serra" (1845, t. VII, 2 trimestre, pp. 196-208); "Plano de uma colônia militar no Brasil" (1841, t. III, 20 trimestre, pp. 228-242); "Breve notícia sobre a colônia de suissos fundada em N ova Friburgo, porThoméda Fonseca e Silva" (1849, t. XII, 2o trimestre, pp. 137-142); "M apa dos IndiosCherenteseCha vantesnanovapovoação deT heresaChristinano rio Tocantins, e dos Indios Charaós da aldêa de Pedro Affonso nas margens do mesmo rio, ao norteda provincia de Goyaz, pelo missionario apostolico capuchinho frei Rafael Tuggia" (1856, t. XIX, 10 trimes tre, pp. 119-124).
Esse consenso em torno da importância da estatística para se conhecer o país formara-se ao longo das primeiras décadas do Segundo Reinado, a partir dos próprios desafios enfrentados pela elite política e pela burocracia imperial no exercício do poder. E firmara-se graças aos esforços interpretativos que foram sendo construídos pela elite intelectual acerca dos contornos da nação e do Estado no Brasil. C omo foi dito anteriormente, o veículo de muitas dessas contribuições era a Revi sta do I nstituto H istórico e G eográfico Brasileiro, que começou a circular em 1839. Em suas páginas podem ser encontrados inúmeros trabal hos que lidavam com o tema da população ou o tangenciavam por meio do estudo da colonização, da catequese, do mapeamento de "vazios" demográficos e outros. Já em seu terceiro núme ro, o secretário perpétuo do instituto, Januário da Cunha Barbosa, e José Silvestre Rebelo desenvolviam o "programa": "Sea introdução dos escravos africanos no Brasil embaraça a civilização dos nossos indígenas" (1839, t. I, 3o trimestre, pp. 159-172). N o ano seguinte, novamente o secretário perpétuo dissertava sobre "Q ual seria hoje o melhor sistema de colonizar os índios entranhados em nossos sertões" (1840, t. II , 10 trimestre, pp. 3-18). E mesmo trabalhos mais próximos à história apresentavam um perfil preocupado em determinar a população, como ocorria com a "M emória, ou informação dada ao G overno sobre a C apitania de M ato-Grosso, por Ricardo Franco de Almeida Serra, Tenente Coronel Engenheiro, em 31 de Janeiro de 1800" (I dem, pp. 19-48), que tinha como objetivo subsidiar um plano de defesa da região contra possíveis ataques dos espanhóis estabelecidos nas margens dos rios Paraguai, Guaporé e M amoré. 0 autor discorria sobre a geografia e a população como um todo, procurando estimá-la tanto do lado português como do espanhol. A “M emória sobre as nações gentias que habitam o Continente do M aranhão - Escrita em 1819 pelo M ajor

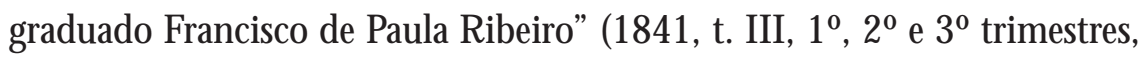
pp. 184-197, 297-322, 442-456) começava falando do estado bárbaro dessa população indígena, "tão prejudicial ao aumento geral desta colônia, como inútil àquele progresso social, que pretendemos haver dos mesmos índios", para em seguida descrever as várias nações e estimar sua população total. Ao longo dos anos, apareceram diversos trabalhos sobre colônias militares ou aldeamentos indígenas ${ }^{33}$. Ademais, surgiram aqueles que abordavam especificamente a população de determinadas regiões, como a "M e mória sobre o descobrimento, governo, população e coisas mais notáveis da capitania de Goiaz: pelo padre Luiz Antônio da Silva Souza", datada de 1812 mas publicada em 1849 (t. XII , 4을 trimestre, pp. 429-510); a “M e- 
mória estatística da Província do Espírito Santo no ano de 1817 por Francisco Alberto Ribeiro", publicada em 1856 (t. XIX, 2o trimestre, pp. 161188); o "Resumo das observações estatísticas feitas pelo engenheiro Luiz D 'Alincourt [...] em 1826", publicado em 1857 (t. XX, 30 trimestre, pp. 345-360); a "D ivisão eclesiástica do Brasil, pelo desembargador Antônio Rodrigues Velloso", de 1819, publicada parcialmente em 1864 (t. XXVII, 20 trimestre, pp. 263-269) e na íntegra em 1866 (t. XXIX, 10 trimestre, pp. 159-199); a "População da capitania de M ato G rosso em 1800", em 1865 (t. XXVIII, 10 trimestre, pp. 123-127); a "M emória e considerações sobre a população do Brasil, por Henrique Jorge Rebello", em 1867 (t. XXX, 1음 trimestre, pp. 5-42); e o "M apa da população da corte e província do Rio de Janeiro em 1821", publicado em 1870 (t. XXXIII, 10 trimestre, pp. 135-142). As inúmeras corografias provinciais publicadas nas páginas da revista do instituto em geral traziam informações sobre a população, como aquelas organizadas por Raimundo José da $C$ unha $M$ attos, depois republicadas em livros (cf. M attos, 1979; 1984). 0 próprio instituto já assumira, em 1843, a determinação de indicar ao governo imperial a necessidade de realizar uma estatística demográfica, e para tanto nomeou uma comissão, composta pelo desembargador Rodrigo de Sousa da Silva Pontes e o tenente-coronel J osé J oaquim M achado de O liveira, que deveria apresentar "um plano de organização estatística, que tenha no seio do Instituto o centro dos trabalhos, que em todas as províncias se devem empreender" (1843, t. V, suplemento, pp. 15-16).

A disseminação de publicações que buscavam organizar os dados pertinentes a determinadas províncias também era um importante elemento de divulgação da importância da estatística para o conhecimento da nação. Podemos encontrar um precursor dessa tendência em $\mathrm{D}$ aniel Pedro M üller, que escreveu, em 1836, o Ensaio d'um quadro etatístico da Província de $S$. Paulo sob encomenda do governo provincial. Dividido em duas partes, a primeira cuidava da "Estatística geográfica e natural" e a segunda tratava da "Estatística política e civil"; nesta tratava-se da população (cf. M üller, 1978). Em Pernambuco, o desembargador Jeronymo M artiniano Figueira de M ello escreveu o Ensaio sobre a estatística civil e política da província de Pernambuco, resultado de um contrato feito com a presidência da província em 27 de fevereiro de 1841, e que foi publicado em 1852 (cf. M ello, 1979). O utra obra da mesma natureza foi a do senador Thomaz Pompeo de Souza Brasil, sobre o Ceará; também encomendada pelo governo provincial, em 1855, e intitulada Ensaio estatístico da Província do Ceará, veio 
34. Paulino José Soares deSouza, pai do homônimo ministro do Império que apresentou 0 projeto de lei do censo de 1872. a público em 1863 (cf. Brasil, 1997). N a década seguinte, disseminar-seiam os dicionários geográficos das províncias, todos preocupados em coligir informações estatísticas (cf. M arquez, 1870, 1878; M arques, 1879). I gualmente importantes foram os trabal hos de Sebastião Ferreira Soares, dos quais se destacam os Elementos de estatistica compreenden do a theoria da sciencia e a sua applicação (cf. Soares, 1865).

É possível afirmar que a segunda metade do século XIX é claramente marcada pela busca de explicações sobre a nação e de justificativas para a ação do Estado com base na compreensão da dinâmica da população brasileira. Assim, o visconde do U ruguai ${ }^{34}$, em seu Ensaio sobre o D ireito administrativo, publicado em 1862, discutia a relevância de uma divisão política, administrativa e judiciária harmônica para que se tivesse uma organização política, administrativa e judiciária eficaz. Essa divisão deveria ser formada com base no território, na população, nos impostos e nos meios de comunicação das regiões. U m problema para o Estado brasileiro residia na "dispersão da população, dispersão cuja tendência é, na frase de um escritor americano, barbarizadora"; esse seria "um dos maiores obstáculos com que temos de lutar, na organização das nossas divisões políticas, administrativas e judiciárias". 0 autor intentou, ainda, uma análise do comportamento migratório dessa população:

Antigamente, nos tempos coloniais, a nossa população atraída pela indústria das minas, e atuada pelo sistema da metrópole, que conservava os nossos portos fechados ao comércio estrangeiro, afluía e dispersava-se pelo interior, o qual assim foi povoado, bem como as nossas mais longínquas fronteiras. Tende hoje a refluir para o litoral, e a aproximar-se de lugares onde possa permutar, e donde Ihe seja possível exportar os produtos da lavoura que constituem a riqueza do país. Isto explica 0 atraso em que vão caindo algumas províncias do interior, cobertas de povoações decadentes, ou estacionárias (U ruguai, 1960).

A aprovação da lei do censo em 1870, portanto, ocorreu em um momento bastante diverso daquele da década de 1850, uma vez que o regime imperial se encontrava consolidado, desfrutando de um amplo consenso interno e mesmo externo, e o fim da Guerra do Paraguai, como bem assinalou o ministro do Império na apresentação do projeto de 1870, abrira uma conjuntura favorável para novas iniciativas por parte do Estado. A importância e o relevo do estudo da população era um consenso firmado no seio da elite política e intelectual, e foi com essa disposição que a buro- 
cracia imperial lançou-se à organização dos trabalhos censitários. Assim como em 1850, o conteúdo do censo e do registro civil não foi debatido pelos parlamentares, ficando a decisão a cargo do governo. Foram os burocratas, por meio dos regulamentos baixados via decretos do poder executivo, que discutiram e deliberaram sobre os aspectos relevantes a serem levantados nas estatísticas. D evo lembrar, todavia, que muitos desses burocratas também eram parlamentares, seguindo o padrão típico da elite política imperial. 0 senador Figueira de M elo, por exemplo, fora presidente da comissão central que executou o censo da Corte, em 1870; daí seu interesse em defender dos ataques do senador Pompeu os seus trabaIhos. $\mathrm{N}$ a mesma comissão estava presente, também, o deputado Andrade Figueira, um dos principais debatedores do projeto quando este ainda se achava na Assembléia Geral.

As categorias censitárias que esses burocratas adotaram refletiam o momento específico que se vivia, articulado com a experiência colonial de que falei anteriormente. D efinir a condição social (livre ou escrava) era uma necessidade ante a divisão básica da sociedade imperial. Conhecer essas categorias era importante para subsidiar as políticas públicas que se implantavam: a Lei do Ventre Livre, a distribuição de eleitores pelas paróquias, o debate sobre a instrução pública, os desafios do saneamento nas grandes cidades.

O utra preocupação era a divisão dos habitantes do país segundo a cor. Como disse anteriormente, a presença do critério de cor nos diversos levantamentos populacionais do século XIX exprimem uma continuidade em face da herança ibérica, desdobrando-se em outras formas de descrição e análise da população brasileira. Essa preocupação aparecia, por exemplo, em discursos raciais explicadores do Brasil, já destacados anteriormente. Para o Brasil, determinar a cor e assim precisar a sua composição racial era mais importante do que outros elementos identificadores da diversidade cultural contida no espaço nacional. $\mathrm{N}$ a Europa, à mesma época, essa preocupação foi canalizada sobretudo para a identificação das diversas línguas e dialetos que conviviam em um mesmo Estado nacional ou que se espalhavam por vários deles. $\mathrm{N}$ os $\mathrm{C}$ ongressos Internacionais de Estatística que se sucederam desde meados do século XIX, debates acirrados foram travados em torno da necessidade dessa categoria nos censos nacionais. Apenas a partir do Congresso de São Petersburgo, em 1872, houve a recomendação de incluir a língua entre as questões a serem levantadas (cf. H obsbawm, 1990, pp. 117-118). Estava em jogo, evidentemente, a utilização da língua 
para definir a nação. 0 reconhecimento de uma diversidade lingüística em determinados Estados (especialmente aqueles de feição imperial, como 0 I mpério Austro-H úngaro) poderia abrir caminho para reivindicações de autonomia nacional. O ra, o Congresso de São Petersburgo foi aquele em que o Brasil participou pela primeira vez. Em seu relatório, porém, o representante oficial do Brasil, barão de Porto Seguro, não mencionou essa resolução acerca da língua, deixando clara sua pouca relevância para o caso brasileiro (cf. Porto Seguro, 1872).

A legislação do censo abortado de 1852 previa a identificação das tribos a que pertenciam os indígenas ou caboclos. Em 1872, desapareceu essa preocupação, embora se tenha explicitado a necessidade de declarar a cor. A identificação das tribos indígenas seria aquilo que mais se aproximaria da preocupação com a língua expressa nos congressos estatísticos. Entretanto, sua supressão em 1872 aponta para a visão de que o Brasil não conhecia problemas de divisões internas, o que reforçava a convicção de uma identidade estreita entre o Estado imperial e a nação brasileira.

Alguns anos após a realização dos trabalhos censitários, em 1878, os resultados eram publicados. 0 censo de 1872 foi bastante eficaz em dar uma resposta ao anseio da elite letrada imperial por uma descrição da nação, a qual refletia em suas clivagens aquilo que a elite gostaria de ver: uma nação homogênea quanto aos aspectos culturais, mas hierarquizada quanto à sua condição social e quanto à cor. A preocupação com a cor seria o foco das indagações, nas décadas seguintes, acerca dos destinos da nação. N essa época, estava sendo alvo de reel aboração por parte de uma nova geração de intelectuais, que passava a se preocupar sobretudo com a questão racial.

Epílogo

0 censo de 1872 significou mais um degrau no caminho que a elite imperial construía para alcançar o seu ideal de civilização e progresso. Agora, o Brasil desfrutava de um trabalho que permitiria integrar o país no conjunto das nações cultas. A preocupação com a estatística parecia se consolidar no seio do Estado brasileiro, mas as dificuldades em realizar 0 segundo censo, previsto para 1880, mostraram os limites dessa pretensão. A pós sucessivos adiamentos, apenas em 1890, sob o novo regime republicano, conseguiu-se realizar o trabalho. Fica claro que o censo anterior foi 0 paradigma adotado, e a permanência da preocupação com a cor era uma das demonstrações disso. 
Apenas nos censos seguintes foram introduzidas modificações que apontaram para a redefinição desse paradigma. À parte uma melhor definição das ocupações e dos setores econômicos, o fato crucial foi a exclusão, em 1900 e em 1920, da questão da cor. Já se justificou essa omissão por um possível empenho do regime republicano brasileiro em apagar a memória da escravidão. Entretanto, creio que parte da explicação pode vir do incômodo causado pela constatação de que nossa população era marcada e crescentemente mestiça, enquanto as teses explicativas do Brasil apontavam para os limites que essa realidade colocava à real ização de um ideal de civilização e progresso. As explicações raciais para o Brasil, que ganharam vigor nas décadas finais do século XIX, tendiam a assumir feições cada vez mais pessimistas, dada a constatação empírica da dificuldade, ou mesmo impossibilidade, de se superar esse nosso mal original.

M as uma outra parte da explicação pode vir do aparecimento, na virada do século, de novas perspectivas de análise que tendiam a tratar da construção da nação sob novas óticas. R efiro-me ao surgimento de uma explicação mais "geográfica" para o Brasil, encerrando aí tanto seus limites como suas potencialidades. Foi nesse período que os trabalhos de Euclides da Cunha e de C apistrano de Abreu começaram a indicar a necessidade de se conhecer um outro Brasil, distante das grandes cidades litorâneas. A partir daí, será no sertão que se buscarão muitas das explicações para o país, vendo-o às vezes como um estorvo à civilização, às vezes como o cerne da nacional idadeque deveser resgatado, às vezes simultaneamente como ambas as coisass.

Referências Bibliográficas

Abreu, Regina. (1998), 0 enigma de Os Sertões. Rio de Janeiro, Rocco/Funarte. A Lo nso, Ângela. (2002), I déias em movimento: a geração 1870 na crise do Brasil-Impé rio. São Paulo, Paz e Terra.

Anderson, Benedict. (1989), N ação e consciência nacional. São Paulo, Ática.

Anderson, M argo J. (1988), The American census: a social history. N ew H aven/London, Yale University Press.

Aulete, Francisco Júlio Caldas. (1881), D iccionario contemporaneo da lingua portuguesa. Lisboa, Imprensa N acional.

Barm An, Roderick. (1988), Brazil, the forging of a nation. Princeton, Princeton U niversity Press.

BEndix, Reinhard. (1996), Construção nacional e cidadania. São Paulo, Edusp.
35. Sobre o "sertão" como uma categoria de análise da nacionalidade no pensamento social brasileiro, ver Vidal e Souza (1997), Abreu (1998) e Lima (1999). É importante ressaltar quea contraposição entrelitoral e sertão como elemento explicativo da nacionalidade brasileira integra o que Wanderley Guilherme dos Santos (1978) chamou dematriz dicotômicana análise da nossa realidade social. 
Bluteau, Raphael de. (1712), Vocabulário portugues e latino. Coimbra, Colégio das Artes da Companhia de Jesus.

Botelho, Tarcísio R. (1998), População e nação no Brasil do século XIX. São Paulo.

Tese de D outorado. Faculdade de Filosofia, Letras e Ciências H umanas da U SP.

Brasil, T homaz Pompeo de Sousa. (1997), Ensaio estatístico da Província do Ceará. 1 ạ

edição 1863. Fortaleza, Fundação Waldemar Alcântara.

Burns, E. Bradford. (1968), Nationalism in Brazil. N ew York, Frederick A. Praeger, Publishers.

Carvalho, José M urilo de. (1988), Teatro de sombras. São Paulo/Rio de Janeiro, Vértice/luperj. - (1995), D esenvolvimiento dela ciudadanía en Brasil. M éxico, Fondo deCultura Económica. - (1998), Pontos e bordados: escritos de história e política. Belo H orizonte, Editora da UFM G.

CostA, Emília Viotti da. (1987), "Política de terras no Brasil e nos Estados U nidos". In: D a M onarquia à República: momentos decisivos. São Paulo, Brasiliense, pp. 139-161.

D IAS, M aria O dila da Silva. (1968), "Aspectos da ilustração no Brasil". Revista do Instituto H istórico e Geográfico Brasileiro, Rio de Janeiro, 278: 105-70. . (1986), "A interiorização da metrópole (1808-1853)". In: M отA, Carlos Guilherme (org.), 1822: dimensões. São Paulo, Perspectiva, pp. 160-184.

D o m In GUes, H eloisa M aria Bertol. (1986), "O s intelectuais e o poder na construção da memória nacional". Tempo Brasileiro, Rio de Janeiro, 87: 43-57, out./dez.

FarIA, Eduardo Augusto de. (1859), N ovo diccionario da lingua portuguesa. Rio de Janeiro, Tip. Imperial e Constitucional de J. Villeneuve e Cia., 2 vols.

G ARCIA J r., Afranio. (1993), "Les Intellectuels et la conscience nationale au Brésil". Actes de la Recherche en Sciences Sociales, Paris, 98: 20-33, juin.

G AUER, Ruth M aria C hittó. (2001), A construção do Estado-nação no Brasil: contribuição dos egressos de Coimbra. Curitiba, Juruá.

Gom Es, Ângela de Castro. (1996), H istória e historiadores. Rio de Janeiro, Fundação Getúlio Vargas.

G rah am, Richard. (1997), Clientelismo e política no Brasil do século XIX. Rio de Janeiro, Editora da UFRJ.

Guim ARÃEs, M anoel Luís S. (1988), "N ação e civilização nos trópicos: o Instituto Histórico e G eográfico Brasileiro e o projeto de uma história nacional". Estudos H istóricos, Rio de Janeiro, 1 (1): 5-27.

H oвSBAwm, Eric. (1990), N ações e nacionalismo desde 1780. Rio de Janeiro, Paz e Terra. 
Lım A, N ísia Trindade. (1999), U m sertão chamado Brasil. Rio de Janeiro, Revan/ I uperj/U cam.

LYRA, M aria de Lourdes Viana. (1994), A utopia do poderoso império. Rio de Janeiro, Sette Letras.

M AGn oli, Demétrio. (1997), 0 corpo da pátria. São Paulo, Editora da U nesp/M oderna.

M ARQUES, major M anoel Eufrazio de Azevedo. (1879), Apontamentos históricos, geographicos, biographicos, estatisticos e noticiosos da Provincia de S. Paulo. Rio de Janeiro, Typographia U niversal de Eduardo \& H enrique Laemmert.

M arquez, Cezar Augusto. (1870), D iccionario historico-geographico da Provincia do M aranhão. M aranhão, Typ. do Frias.

- (1878), D iccionario historico, geographico e estatistico da Provincia do Espirito Santo. Rio de Janeiro, Typographia N acional.

M ARTins, José de Souza. (1979), 0 cativei ro da terra. São Paulo, Ciências H umanas.

Martins, M aria do Carmo Salazar Martins. (s/d), 0 censo da Província de M inas Gerais (1833-35). Belo H orizonte, C edeplar/Face/U FM G (mimeo.).

M ATtos, Raimundo José da Cunha. (1979), Corografia Histórica da província de Goiás. Goiânia, Sudeco, Secretaria dePlanejamento eC oordenação G eral do G overno de G oiás. - (1984), Corografia histórica da Província de M inas Gerais. Belo H orizonte/ São Paulo, Itatiaia/Edusp.

M ello, Jeronymo M artiniano Figueira. (1979), Ensaio sobre a estatística civil e política da província de Pernambuco. 1a edição 1852. Recife, Estado de Pernambuco, Conselho Estadual de Cultura.

M оттA, M arly Silva da. (1992), A nação faz cem anos. Rio de Janeiro, Fundação Getúlio Vargas.

M üller, Daniel Pedro. (1978), Ensaio d'um quadro estatístico da Província de S. Paulo. 1836. São Paulo, Governo do Estado de São Paulo.

O liveira, Antônio Rodrigues Velloso de. (1866), "A I greja no Brasil". Revista do Instituto H istórico e Geográfico Brasileiro, Rio de Janeiro, tomo XXIX, parte 1, 1ํtrim.

O liveira, Lúcia Lippi. (1990), A questão nacional na Primeira República. São Paulo, Brasiliense.

PAz, Francisco M oraes. (1996), N a poética da história: a realização da utopia nacional oitocentista. Curitiba, Editora da UFPR.

Pinto, Luis Maria da Silva. (1832), Diccionario da lingua brasileira. O uro Preto, Typographia de Silva.

Porto Seguro, barão de. (1872), Relatório acêrca dos trabalhos do Congresso Estatistico deS. Petersourgo em agosto de 1872, apresentado ao G overno I mperial pel o D el egado O fficial do Brazil, Barão de Porto Seguro. Relatório do M inistério do Império de 1872, Rio de Janeiro. 
Q ueIRoz, M aria I saura Pereira de. (1989), "I dentidade cultural, identidade nacional no Brasil". Tempo Social, São Paulo, 1 (1): 29-46.

Ress, Elisa P. (1985), "O Estado nacional como ideologia: o caso brasileiro". Estudos H istóricos, Rio de Janeiro, 1 (2): 187-203.

RibeIRo, M aria Eurydice de Barros. (1995), O s símbolos do poder. Brasília, Editora da $U n B$.

Santos, Afonso Carlos M arques dos. (1985), "A invenção do Brasil: um problema nacional?". Revista de H istória, São Paulo, 118: 3-12, jan./jun. . (1986), "M emória, história, nação: propondo questões". Tempo Brasileiro. Rio de Janeiro, 87: 5-13, out./dez.

Santos, Wanderley Guilherme dos. (1978), O rdem burguesa e liberalismo político. São Paulo, D uas Cidades.

Schwarcz, Lilia M oritz. (1993), 0 espetáculo das raças. São Paulo, Cia. das Letras. Silva, Antônio de Moraes. (1813), Diccionário da lingua portuguesa recopilado dos vocabularios impressos até agora. Lisboa, Typographia Lacerdina. - (1891), D iccionario da lingua portuguesa recopilado dos vocabularios impressos até agora. Lisboa.

SiLva, Joaquim N orberto de Souza e. (1986), Investi gação sobre os recenseamentos da população geral do Império e de cada província de per si tentados desde os tempos coloniais até hoje. 1ạ edição 1870. São Paulo, IPE/U SP.

SILVA, Rogério Forastieri. (1997), Colônia e nativismo. São Paulo, H ucitec.

Sм IтH, Roberto. (1990), Propriedade da terra e transição. São Paulo/Braślia, Brasiliense/C N Pq.

So ARES, Antônio Joaquim de M acedo. (1875), D iccionario brasileiro da lingua portuguesa. Rio de Janeiro. 2 vols.

SOARES, Sebastião Ferreira. (1865), Elementos de estatistica compreendendo a theoria da sciencia e a sua applicação. Rio de Janeiro, Typographia N acional.

Tilly, Charles. (1996), Coerção, capital eEstados europeus, 990-1992. São Paulo, Edusp. U RUGUAI, visconde do. (1960), Ensaio sobre o D ireito Administrativo. 1ạ edição 1862. Rio de Janeiro, INL.

VIDAL E SouzA, Candice. (1997), A pátria geográfica. G oiânia, Editora da U FG. 


\section{Resumo}

Censos e construção nacional no Brasil Imperial

Este artigo anal isa como o tema "nação" searticulou, no século XIX, com as tentativas de realizar os primeiros levantamentos censitários brasileiros, especialmente em 1852 eem 1872. Traça-se um paralelo entre a necessidade sentida pela elite política nacional de real izar censos gerais e o processo de construção da nação, que acompanha o processo de construção do Estado. Identificando já no século XIX o início desse processo, procuro mostrar que os cen sos podem ser pensados como elementos articulados a ele. D a mesma forma, o Recenseamento Geral do I mpério de 1872 forneceu pela primeira vez um retrato da nação no que diz respeito ao povo que a constituía, realizando uma significativa representação da nação.

Palavras-chave: Censo; Construção nacional; C onstrução do Estado; Brasil Imperial.

\section{Abstract}

Census and nation building in the Brazilian Empire

This article analyses the censuses in XIX $X^{\text {th }}$ century Brazil, especially in 1852 and in 1872 , as a part of the nation building process. I trace a parallel between the necessities of national censuses perceived by the national political elites and the processes of nation and state building. I show that censuses can be considered a part of this process, articulating bureaucratic necessities and symbolic dimensions for the nation building process. In this sense, the Imperial General Census of 1872 exhibited, for the first time, a portrait of the nation, showing the face of Brazilian people and supporting a representation of the nation.

Keywords: Census; N ation building; State building; Imperial Brazil.

Texto recebido em 30/ 10/2003 e aprovado em 31/3/2004.

Tarcísio R. Botelho é professor do M estrado em Ciências Sociais: G estão das Cidades, da PUC-M inas. E-mail: tbotelho@pucminas.br. 